in vivo $34: 1941-1949(2020)$

doi:10.21873/invivo.11991

\title{
Impact of Antiplatelet and Anticoagulant Therapies on Platelet-related Prognostic Markers in Patients With Esophageal Cancer
}

\author{
YUSUKE ISHIBASHI, HIRONORI TSUJIMOTO, KEITA KOUZU, YUJIRO ITAZAKI, SATOSHI TSUCHIYA, \\ SEIICHIRO FUJISHIMA, YOSHIHISA YAGUCHI, HIDEKAZU SUGASAWA, SHINSUKE NOMURA, \\ NOZOMI ITO, MANABU HARADA, HIROMI NAGATA, EIJI SHINTO, YOJI KISHI and HIDEKI UENO \\ Department of Surgery, National Defense Medical College, Saitama, Japan
}

\begin{abstract}
Background/Aim: In recent years, platelet-related markers were recognized as useful prognostic factors in various malignancies. We investigated the relationship between platelet-related prognostic markers and anti-platelet or anti-coagulant therapies for survival outcomes in esophageal squamous cell carcinoma. Patients and Methods: Preoperative platelet-related prognostic markers were evaluated from peripheral blood testing and statistical analyses were performed to evaluate the prognostic value of these markers and reveal the effects of antiplatelets and/or anticoagulants regarding their prognostic relevance. Results: In all 176 patients, preoperative platelet-to-lymphocyte ratio (PLR) was not found to be a predictor of overall survival (OS). However, in patients without antiplatelet or anticoagulant therapies, PLR was significantly associated with a poor $O S(p=0.03)$. Although platelet large cell ratio $(P-L C R)$ was not associated with the prognosis in patients with antiplatelet and/or anticoagulant therapies, higher $P$ LCR was associated with a poor prognosis in patients without antiplatelet or anticoagulant therapies $(p<0.0001)$. Conclusion: Researching detailed antiplatelet and anticoagulant therapies could reinforce the prognostic value of platelet-related prognostic markers in ESCC.
\end{abstract}

Esophageal cancer is the eighth most common diagnosed cancer in the world, with a persistent high mortality rate due to its late-stage diagnosis and rapid progression; the 5-year

This article is freely accessible online.

Correspondence to: Hironori Tsujimoto, MD, Ph.D. Department of Surgery, National Defense Medical College, 3-2 Namiki, Tokorozawa, Saitama 359-8513, Japan. Tel: +81 429951637, Fax: +81 429965205, e-mail: tsujihi@ndmc.ac.jp

Key Words: Esophageal cancer, platelet-to-lymphocyte ratio, prognostic factors. survival rate ranges from $15 \%$ to $25 \%$. Recently, several immunoinflammatory markers, such as the neutrophil-tolymphocyte ratio (NLR), platelet-to-lymphocyte ratio (PLR), and $\mathrm{C}$-reactive protein-to-albumin ratio (CAR), have been reported to have prognostic relevance in various malignancies (1-8). However, several studies have failed to discover the prognostic value of PLR in esophageal cancer (9-11). Although immunoinflammatory markers are easily affected by various factors, such as neoadjuvant chemotherapy (NAC), smoking history, comorbidities, and the use of antiplatelet and anticoagulant drugs, little is known regarding the effect of these factors on the prognostic relevance of immunoinflammatory markers. In recent years, antiplatelet and anticoagulant therapies have been reported to reduce cardiovascular events, and the number of patients taking these drugs has increased $(12,13)$.

The present study aimed to investigate the effect of antiplatelet and anticoagulant drug use on platelet-related prognostic markers such as PLR, platelet distribution width (PDW), mean platelet volume (MPV), and platelet large cell ratio (P-LCR) in patients with resectable esophageal squamous cell carcinoma (ESCC).

\section{Patients and Methods}

Patients. A total of 176 patients diagnosed with ESCC who underwent curative transthoracic esophageal resection at the National Defense Medical College Hospital (Tokorozawa, Japan) from January 2009 to December 2016 were included in the present study. The mean \pm standard deviation age was $70.1 \pm 8.4$ years (range $=43-90$ years). Of the 176 patients, 25 (14\%) were women and $151(86 \%)$ were men. NAC using 5-fluorouracil and cisplatin was administered to $95(54 \%)$ patients; the remaining $81(46 \%)$ did not receive NAC (14). The tumor node metastasis criteria from the eighth edition of the Union for International Cancer Control classification system were used for tumor staging (15). One hundred twenty-seven (72\%) patients underwent video-assisted thoracoscopic esophagectomy, and 49 (28\%) underwent conventional open transthoracic surgery. We preoperatively evaluated platelet-related prognostic markers, 
including PLR, PDW, MPV, and P-LCR. In the patients who underwent NAC, we used the sample before the first infusion of chemotherapy to avoid the effect associated with NAC. The history of antiplatelet and anticoagulant use was described according to the medical and nursing charts, and the patients were interviewed by the doctors in charge.

All the patient demographics were collected from a computer database, including pathological findings, surgical procedures, and overall survival (OS). The OS time was calculated from the day of surgery to the day of death due to any cause. Cancer-specific survival (CSS) time was calculated from the day of surgery to the day of death due to any cancerous cause. Patients who survived were all censored in our survival analyses. All the patients in this study were observed at our hospital or at the outpatient clinic at 3- or 4-month intervals during the first 2 years of the study and every 6 or 12 months thereafter for 3 years. Tumor markers and computed tomography scans were performed every 6 months until 5 years after the surgical resection. After 5 years, annual follow-ups were performed through telephone conversations with the patients, the patient's family members, or their practitioners. Written informed consent was obtained from all patients. The Institutional Review Board of the National Defense Medical College Hospital approved this protocol.

Surgical procedure. We performed conventional open transthoracic esophagectomy with two- or three-field lymphadenectomy through the right fifth or sixth thoracotomy for 49 patients. When using videoassisted thoracoscopic surgery (VATS), three ports with diameters of $12 \mathrm{~mm}$ were inserted after each patient was in the prone position (16). After thoracoscopy, laparoscopy-assisted surgery for gastric tube reconstruction was performed (17). When using conventional open surgery, a circular stapler (CEEA; Covidien, Tokyo, Japan) was used for either cervical or intrathoracic anastomosis, depending on the tumor location. For the VATS, the same stapler was used in the case of intrathoracic anastomosis; a hand-sewn anastomosis was employed in the case of cervical anastomosis.

Platelet-related prognostic markers. PLR was defined as the absolute platelet count divided by the absolute lymphocyte count. The optimal cutoff value for platelet-related prognostic markers was determined according to the time-dependent receiver operating characteristic (ROC) curve for censored 3-year survival (PLR, 151; platelets, 221,000 cells/ $\mu$; lymphocytes, 1,652 cells/ $\mu$ l; PDW, 11.0 fL; MPV, 9.8 fL; P-LCR, 27.8\%).

Antiplatelet and anticoagulant therapies. Of the 176 patients included in this study, $28(15.9 \%)$ underwent antiplatelet and/or anticoagulant therapies; $15(8.5 \%)$ had antiplatelet therapy; 17 (9.6\%) had anticoagulant therapy; 4 (2.3\%) had both antiplatelet and anticoagulant therapy; and $148(84.0 \%)$ had neither antiplatelet nor anticoagulant therapy. Within at least 1 week before surgery, these therapies were stopped to avoid the complications associated with major bleeding.

Statistical analysis. All statistical analyses were performed using JMP 14.0 (SAS Institute Inc., Cary, NC, USA). Time-dependent ROC curves for censored 3-year survival were constructed to estimate the optimal cutoff value of the preoperative PLR, platelet counts, lymphocyte counts, PDW, MPV, and P-LCR. The MannWhitney $U$ or Chi-squared tests were used for the statistical analyses. Hazard ratios (HR) with $95 \%$ confidence intervals $(95 \%$ $\mathrm{CI}$ ) and OS curves using the Kaplan-Meier method were employed.
Differences were compared using the log-rank test. Not only Logrank test, Wilcoxon tests were also performed to balance for the low number of included patients as well as patients with comorbidities, and further validate presented data with statistical significance. Univariate and multivariate analyses were performed to determine the most influential factor on the prognosis. All $p$ values of $<0.05$ were considered statistically significant.

\section{Results}

The relationships between clinicopathological characteristics and patient groups based on PLR, platelet counts, PDW, MPV, and P-LCR are shown in Table I. Preoperative PLR, platelet counts, PDW, and MPV had strong associations with pathological tumor depth $(p=0.02, p=0.03, p=0.0002, p=0.02$, respectively). PLR and P-LCR were associated with the pathological stage $(p=0.01, p=0.02$, respectively). PLR, PDW, and MPV were associated with the frequency of NAC ( $p=0.01, p=0.002, p=0.02$, respectively).

The platelet counts and mean values of PDW, MPV, and P-LCR did not differ between the patients receiving antiplatelet and/or anticoagulant therapies and those who did not (Table II). The predictive values for OS of the PLR, platelet counts, PDW, MPV, and P-LCR were assessed by the area under the ROC (AUROC) curve (Figure 1). The AUROC of P-LCR was highest (AUROC $=0.632$ ) compared with that of PLR, platelets, PDW, and MPV (AUROC $=0.539,0.529,0.559,0.534$, respectively).

Although preoperative PLR was not associated with the OS in patients with antiplatelet and/or anticoagulant therapies ( $p=0.42$, respectively), PLR was significantly associated with OS in patients without these therapies $(p=0.03$ ) (Figure 2). In addition, PLR was associated with CSS in patients without either therapy, but not in patients with antiplatelet and/or anticoagulant therapies (Figure 3).

Platelet counts, PDW, and MPV did not affect the prognosis even when considering the use of antiplatelet and anticoagulant therapies (Figure 4). Although patients without antiplatelet or anticoagulant therapies $(p<0.0001)$ with high P-LCR had a poorer survival than those with low P-LCR, PLCR was not associated with the prognosis in patients with antiplatelet and/or anticoagulant therapies $(p=0.69)$.

To remove the effect of antiplatelet and/or anticoagulant therapies on the result, we performed univariate and multivariate analyses of factors in patients without antiplatelet or anticoagulant therapies; tumor depth and PLCR were independent prognostic factors and PLR was not (Table III).

\section{Discussion}

In the present study, we investigated the impact of antiplatelet and anticoagulant therapies on the prognostic value of platelet-related markers in patients who underwent 


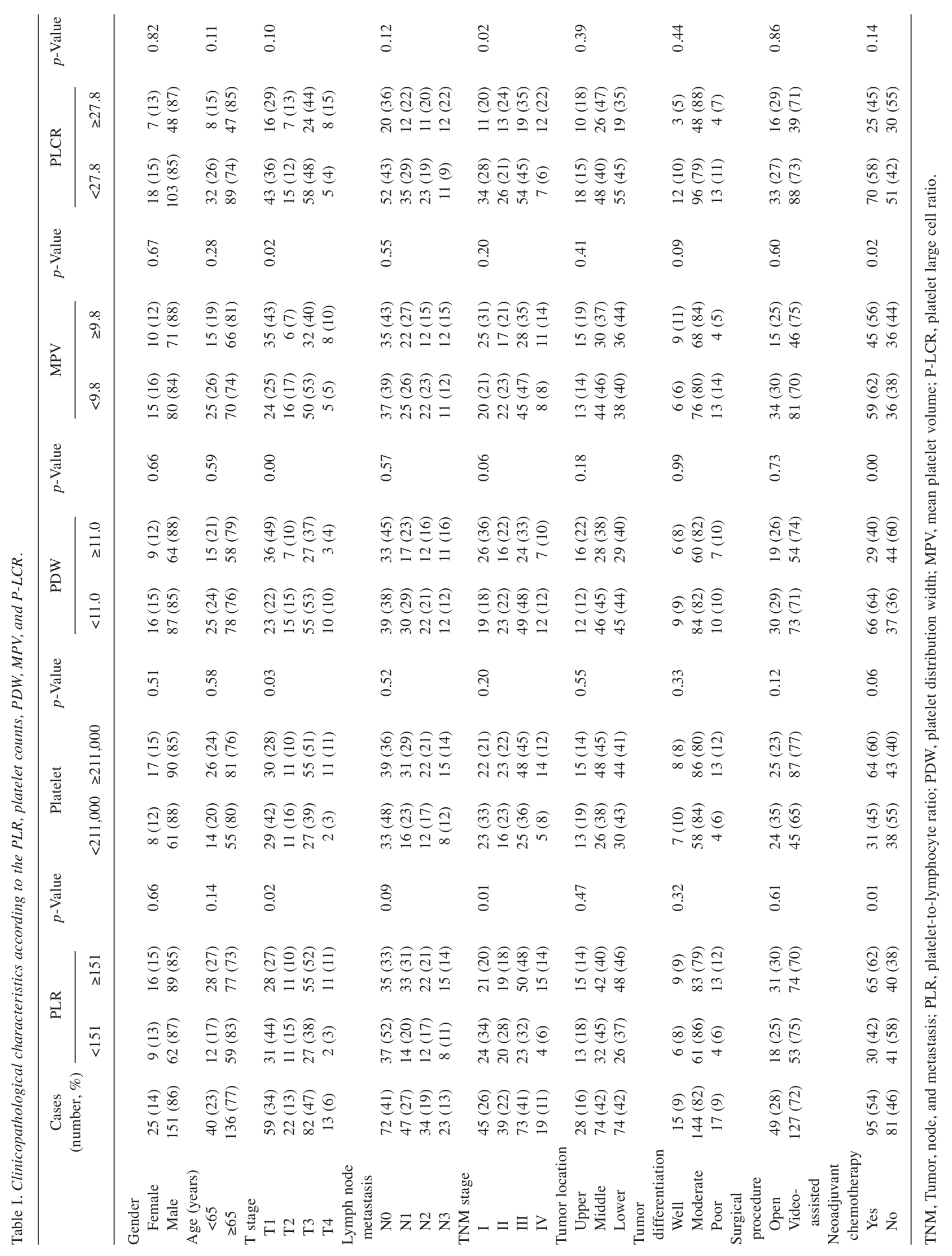



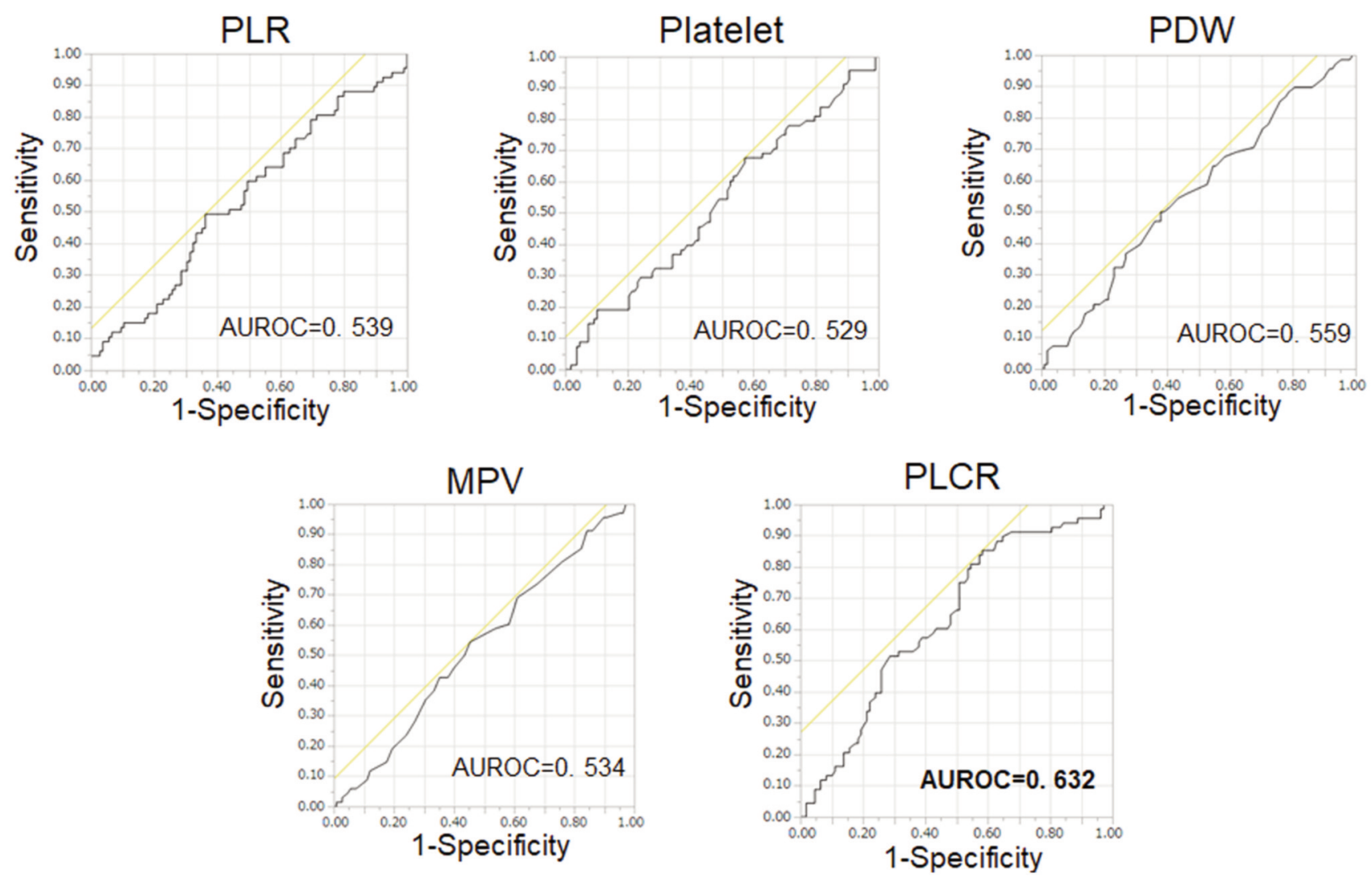

Figure 1. Time-dependent ROC for censored 3 years survival and AUROC were evaluated to verify the accuracy of PLR, platelet counts, PDW, $M P V$, and P-LCR for survival prediction. AUROC of P-LCR was highest compared with that of PLR, platelets, PDW, and MPV. ROC, Receiver operating curve; AUROC, area under the ROC; PLR, platelet-to-lymphocyte ratio; PDW, platelet distribution width; MPV, mean platelet volume; $P$-LCR, platelet large cell ratio.

Table II. Comparison of platelet counts, PDW, MPV, and P-LCR between patients with antiplatelet and/or anticoagulant therapies and patients without antiplatelet or anticoagulant therapies.

\begin{tabular}{|c|c|c|c|c|c|c|c|c|c|}
\hline & Patient number & Platelet count & $p$-Value & PDW & $p$-Value & MPV & $p$-Value & PLCR & $p$-Value \\
\hline $\begin{array}{l}\text { With antiplatelet and/or } \\
\text { anticoagulant therapies }\end{array}$ & 28 & $243,000 \pm 16,226$ & 0.70 & $11.06 \pm 0.35$ & 0.67 & $10.0 \pm 0.17$ & 0.63 & $26.5 \pm 1.52$ & 0.1 \\
\hline $\begin{array}{l}\text { Without antiplatelet nor } \\
\text { anticoagulant therapies }\end{array}$ & 148 & $249,612 \pm 7,058$ & & $10.89 \pm 0.15$ & & $9.9 \pm 0.07$ & & $23.9 \pm 0.66$ & \\
\hline
\end{tabular}

PDW, Platelet distribution width; MPV, mean platelet volume; P-LCR, platelet large cell ratio.

curative esophageal resection for ESCC. We found that although PLR was not associated with OS in the overall cohort, PLR was significantly associated with OS in patients who had not been administered antiplatelet and/or anticoagulant medications.

Increasing numbers of studies have reported the prognostic value of PLR in various malignancies; however, the biological mechanism of this phenomenon remains controversial $(9,18$ -
21). Feng et al. (2) investigated the prognostic value of NLR and PLR in patients with esophageal cancer and concluded that they were significant predictors of OS in patients with esophageal cancer and that PLR was superior to NLR as a predictive factor, on the basis of ROC curves. On the other hand, several other studies did not report a prognostic value for PLR (9-11). Our previous systematic meta-analysis also showed that an absence of association between PLR and OS, 

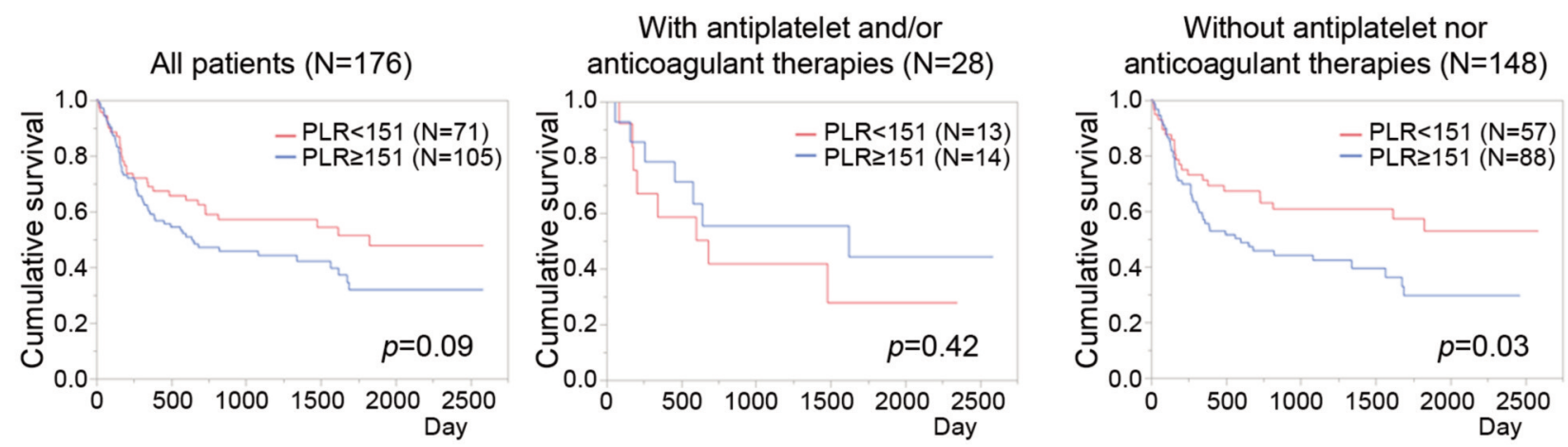

Figure 2. Overall survival after esophagectomy for ESCC according to preoperative PLR in all patients, patients with antiplatelet and/or anticoagulant therapies, and patients without antiplatelet or anticoagulant therapies. PLR was significantly associated with OS in patients without antiplatelet and/or anticoagulant therapies, but not in patients with antiplatelet and/or anticoagulant therapies. ESCC, Esophageal squamous cell carcinoma; PLR, platelet-to-lymphocyte ratio.
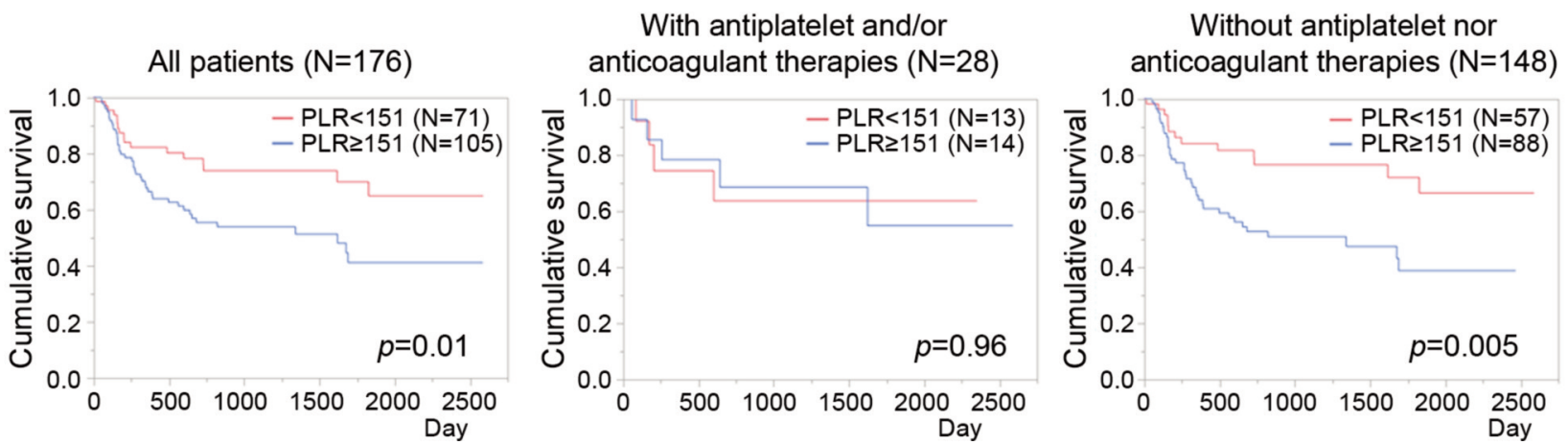

Figure 3. Cancer-specific survival after esophagectomy for ESCC according to preoperative PLR in all patients, patients with antiplatelet and/or anticoagulant therapies, and patients without antiplatelet nor anticoagulant therapies. PLR was associated with CSS in patients without either therapy, but not in patients with antiplatelet and/or anticoagulant therapies. ESCC, Esophageal squamous cell carcinoma; PLR, platelet-tolymphocyte ratio.

though NLR and CAR was significantly associated with prognosis (22). In the present study, PLR was associated with the prognosis in patients without antiplatelet or anticoagulant therapies; in patients with these therapies; however, PLR was not related to prognosis.

We speculated that the platelet functional changes associated with antiplatelet or anticoagulant therapies may affect the clinical relevance of PLR in patients with these therapies. Neutrophil extracellular traps (NETs) are recently recognized mechanisms that are released from tumorassociated neutrophils and form a physical barrier between cancer cells and immunocompetent cells. Thus, cancer cells can escape the immune response due to the NET barrier and tumor migration is promoted (23). In a mouse model, Lapponi et al. (24) and Caudrillier et al. (25) reported inhibition of NET formation by antiplatelet drugs. Similar theories have also been reported regarding platelet cells.
Holmes et al. (26) reported that platelet cells provide a procoagulant surface, increasing amplification of cancerrelated coagulation, and they can be recruited to tumor cells, shielding them from immune responses and improving cancer growth and dissemination. Wenzel et al. reported success in reducing pulmonary metastases in a murine model of breast cancer using the antiplatelet drug, cilostazol, which decreased platelet aggregability and platelet-tumor complex formation (27). In clinical research, many reports have demonstrated the benefit of antiplatelet drugs regarding incidence or mortality of malignancies, such as colorectal cancer, ovarian cancer, and esophageal cancer (28-30).

PDW, MPV, and P-LCR are often used to measure platelet size and as surrogate markers of platelet activation (31). Several studies have reported that high PDW and MPV were poor prognostic markers in various malignancies (32-34). PLCR is often reported as a prognostic factor in coronary 

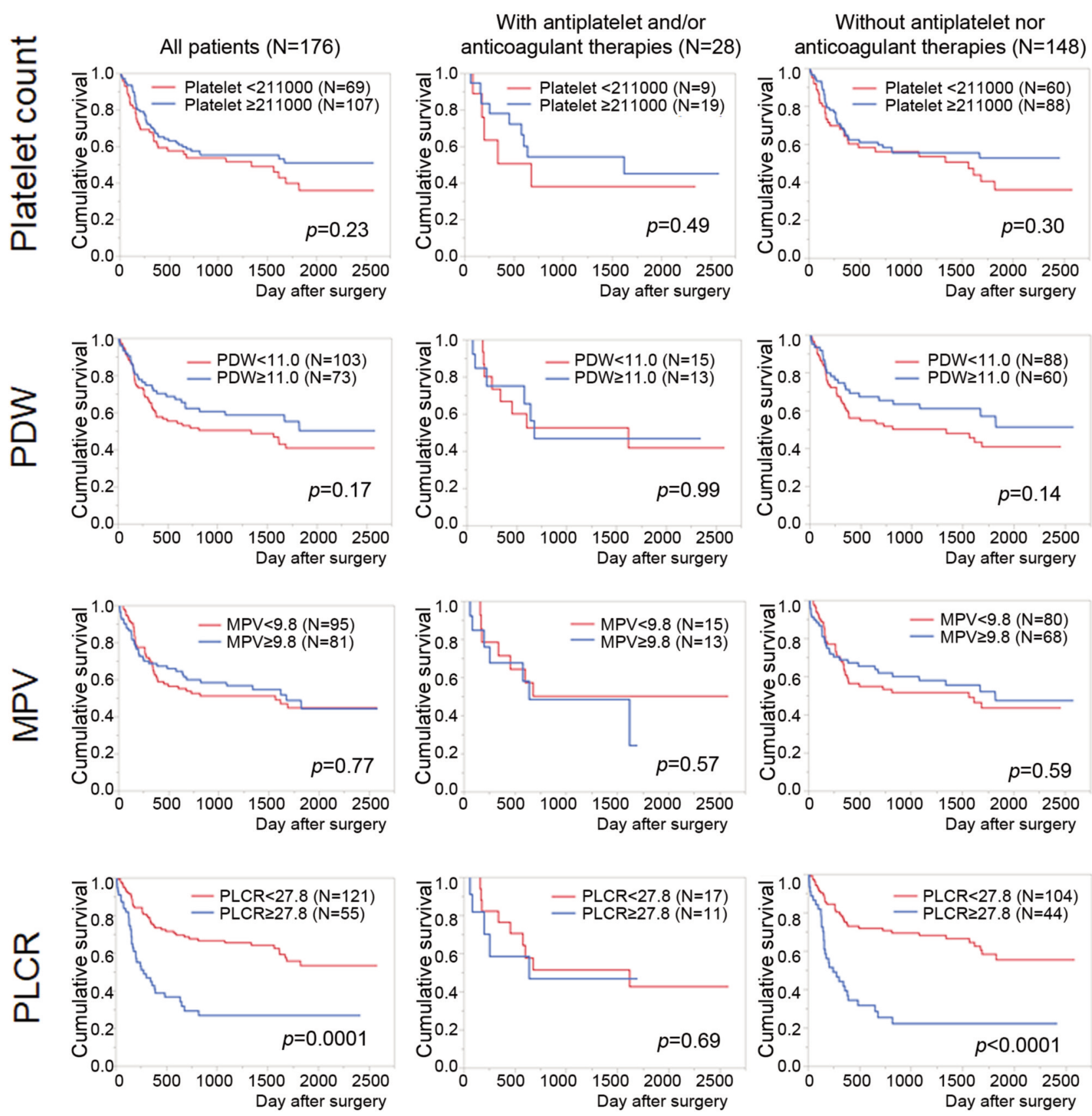

Figure 4. Overall survival after esophagectomy for ESCC according to preoperative platelet counts, PDW, MPV, and P-LCR according to antiplatelet and anticoagulant use. Although patients without antiplatelet or anticoagulant therapies with high P-LCR had poorer survival than those with low $P-L C R, P-L C R$ was not associated with the prognosis in patients with antiplatelet and/or anticoagulant therapies. ESCC, Esophageal squamous cell carcinoma; PDW, platelet distribution width; MPV, mean platelet volume; P-LCR, platelet large cell ratio.

artery disease and myocardial infarction, but has never been associated with cancer prognoses (35).

To reveal how antiplatelet and/or anticoagulant therapies affect PLR, we further investigated PDW, MPV, and P-LCR, which we considered to be morphologically associated with PLR. From our results, platelet counts, PDW, and MPV were not related to prognosis even when considering antiplatelet and/or anticoagulant therapies. High P-LCR levels in patients without antiplatelet or anticoagulant therapies were related to poor survival, but P-LCR was not associated with the prognosis in patients with these therapies; this result was very similar to that of PLR. Strangely, the mean values of PLCR were not different according to the use of antiplatelet and/or anticoagulant therapies. The median survival time of 
Table III. Univariate and multivariate analyses that could affect overall survival of patients with ESCC (patients without antiplatelet or anticoagulant therapies).

\begin{tabular}{|c|c|c|c|c|}
\hline & $\begin{array}{c}\text { Univariate } \\
\text { analysis } \\
\text { HR }(95 \% \mathrm{CI})\end{array}$ & $p$-Value & $\begin{array}{c}\text { Multivariate } \\
\text { analysis } \\
\text { HR }(95 \% \mathrm{CI})\end{array}$ & $p$-Value \\
\hline \multicolumn{5}{|l|}{ Gender } \\
\hline Female & Ref. & 0.0442 & Ref. & 0.0221 \\
\hline Male & $2.361(1.111-6.106)$ & & $2.400(1.120-6.241)$ & \\
\hline \multicolumn{5}{|l|}{ Age (years) } \\
\hline $\begin{array}{l}<65 \\
\geq 65\end{array}$ & $\begin{array}{c}\text { Ref. } \\
1.343(0.773-2.505)\end{array}$ & 0.3207 & & \\
\hline \multicolumn{5}{|c|}{ Tumor depth } \\
\hline $\mathrm{T} 1-\mathrm{T} 2$ & Ref. & $<0.0001$ & Ref. & $<0.0001$ \\
\hline T3-T4 & $3.204(1.916-5.620)$ & & $2.955(1.736-5.262)$ & \\
\hline \multicolumn{5}{|c|}{$\begin{array}{l}\text { Lymph node } \\
\text { metastasis }\end{array}$} \\
\hline N0-N1 & Ref. & 0.0617 & & \\
\hline $\mathrm{N} 2-\mathrm{N} 3$ & $1.586(0.965-2.554)$ & & & \\
\hline \multicolumn{5}{|l|}{$\begin{array}{l}\text { Tumor } \\
\text { location }\end{array}$} \\
\hline $\begin{array}{c}\text { Lower/ } \\
\text { middle }\end{array}$ & Ref. & 0.2019 & & \\
\hline Upper & $1.448(0.790-2.490)$ & & & \\
\hline \multicolumn{5}{|c|}{$\begin{array}{l}\text { Tumor } \\
\text { differentiation }\end{array}$} \\
\hline $\begin{array}{l}\text { Well/ } \\
\text { moderate }\end{array}$ & Ref. & 0.1053 & & \\
\hline Poor & $1.740(0.837-3.246)$ & & & \\
\hline \multicolumn{5}{|l|}{$\begin{array}{l}\text { Surgical } \\
\text { procedure }\end{array}$} \\
\hline $\begin{array}{l}\text { Video- } \\
\text { assisted }\end{array}$ & Ref. & 0.0743 & & \\
\hline Open & $1.536(0.949-2.449)$ & & & \\
\hline \multicolumn{5}{|l|}{ PLR } \\
\hline$<151$ & Ref. & 0.0279 & Ref. & 0.0848 \\
\hline$\geq 151$ & $1.721(1.059-2.880)$ & & $1.555(0.942-2.642)$ & \\
\hline \multicolumn{5}{|l|}{ PDW } \\
\hline$<11$ & Ref. & 0.1430 & & \\
\hline$\geq 11$ & $0.7021(0.428-1.124)$ & & & \\
\hline \multicolumn{5}{|l|}{ MPV } \\
\hline$<9.8$ & Ref. & 0.5448 & & \\
\hline$\geq 9.8$ & $0.8669(0.541-1.374)$ & & & \\
\hline \multicolumn{5}{|l|}{ PLCR } \\
\hline$<27.8$ & Ref. & $<0.0001$ & Ref. & $<0.0001$ \\
\hline$\geq 27.8$ & $3.157(1.957-5.065)$ & & $3.518(2.138-5.773)$ & \\
\hline
\end{tabular}

ESCC, Esophageal squamous cell carcinoma; HR, hazard ratio; CI, confidence interval; Ref., reference; PLR, platelet-to-lymphocyte ratio; PDW, platelet distribution width; MPV, mean platelet volume; P-LCR, platelet large cell ratio.

patients with high P-LCR receiving antiplatelet therapies was 56.5 months, which was higher than that in patients without antiplatelet therapies (8.2 months). We speculated that large platelet cells might be associated with greater platelet-tumor complex formation than might normal-sized platelet cells; therefore, patients with high P-LCR could gain more benefit from antiplatelet drugs than could patients with low P-LCR levels. Furthermore, in our study, we found that the AUROC of P-LCR was highest compared with other platelet-related factors and was the only independent prognostic factor among these measures in the multivariate analysis. Although P-LCR has never been associated with cancer prognoses, future studies should reveal the association between P-LCR and cancer prognoses, while also considering antiplatelet and/or anticoagulant therapies.

The present study had certain limitations. First, it was conducted at a single institution using a retrospective design, with a relatively small number of patients, especially patients undergoing antiplatelet and/or anticoagulant therapies. The patients who underwent antiplatelet or anticoagulant therapy sometimes had severe comorbidities, such as heart disease and cerebrovascular disease; therefore, indication for surgical resection was limited with them.

Second, the best approach to determine the cutoff value of PLR remains controversial. Most studies have used a timedependent ROC curve, which is also the approach we adopted; however, several studies had used median values or cutoff value previously reported. Therefore, the PLR cutoff value varied from 120 to 244 in these studies, and these heterogeneities should be resolved in the future.

Third, Guo et al. reported that NLR and use of anti-biotic drugs effected on prognosis in ESCC patients. (1) Not only antiplatelet and/or anticoagulant therapies but also any other medications should be considered its effects on these values.

In conclusion, the investigation of preoperative plateletrelated prognostic markers for survival outcomes might need to include the effects of antiplatelet and anticoagulant therapies. More and larger studies with a prospective analysis should be mandated to clearly confirm the results. In this study, in particular, the result that antiplatelet therapy might improve the prognoses of patients with high PLR and P-LCR who were primary worse than lower groups should be verified by future prospective clinical studies.

\section{Conflicts of Interest}

The Authors declare no conflicts of interest regarding this article.

\section{Authors' Contributions}

YI, HT, HN, YY, KK, ST, YI, SF, SN, NI, MH, HS, and ES helped to draft the manuscript. YK and $\mathrm{HU}$ have revised manuscript critically. All Authors read and approved the final manuscript.

\section{Acknowledgements}

The Authors have no conflicts of interest to disclose and received no financial support for this study. All Authors certify that they have no commercial associations that might pose a conflict of interest about submitted article. 


\section{References}

1 Hirahara N, Tajima Y, Fujii Y, Yamamoto T, Hyakudomi R, Hirayama T, Taniura T, Ishitobi K, Kidani A and Kawabata Y: A novel prognostic scoring system using inflammatory response biomarkers for esophageal squamous cell carcinoma. World J Surg 42(1): 172-184, 2018. PMID: 28744596. DOI: 10.1007/ s00268-017-4144-y

2 Feng JF, Huang Y and Chen QX: Preoperative platelet lymphocyte ratio (plr) is superior to neutrophil lymphocyte ratio (nlr) as a predictive factor in patients with esophageal squamous cell carcinoma. World J Surg Oncol 12: 58, 2014. PMID: 24641770. DOI: 10.1186/1477-7819-12-58

3 Sharaiha RZ, Halazun KJ, Mirza F, Port JL, Lee PC, Neugut AI, Altorki NK and Abrams JA: Elevated preoperative neutrophil: Lymphocyte ratio as a predictor of postoperative disease recurrence in esophageal cancer. Ann Surg Oncol 18(12): 3362-3369. 2011. PMID: 21547702. DOI: 10.1245/s10434-011-1754-8

4 Yang X, Huang Y, Feng J-F and Liu J-S: Prognostic significance of neutrophil-to-lymphocyte ratio in esophageal cancer: A metaanalysis. Onco Targets Ther 8: 789-794, 2015. PMID: 25914549. DOI: $10.2147 / O T T . S 77099$

$5 \mathrm{Xu} \mathrm{X-L,} \mathrm{Yu} \mathrm{H-Q,} \mathrm{Hu} \mathrm{W,} \mathrm{Song} \mathrm{Q} \mathrm{and} \mathrm{Mao} \mathrm{W-M:} \mathrm{A} \mathrm{novel}$ inflammation-based prognostic score, the c-reactive protein/albumin ratio predicts the prognosis of patients with operable esophageal squamous cell carcinoma. PLoS One 10(9): e0138657, 2015. PMID: 26390126. DOI: 10.1371/journal.pone. 0138657.

6 Wei X-1, Wang F-h, Zhang D-s, Qiu M-z, Ren C, Jin Y, Zhou Y$\mathrm{x}$, Wang D-s, He M-m and Bai L: A novel inflammation-based prognostic score in esophageal squamous cell carcinoma: The creactive protein/albumin ratio. BMC Cancer 15(1): 350, 2015. PMID: 25934640. DOI: 10.1186/s12885-015-1379-6

7 Miyazaki T, Sakai M, Sohda M, Tanaka N, Yokobori T, Motegi Y, Nakajima M, Fukuchi M, Kato H and Kuwano H: Prognostic significance of inflammatory and nutritional parameters in patients with esophageal cancer. Anticancer Res 36(12): 65576562, 2016. PMID: 27919983. DOI: 10.21873/anticanres.11259

8 Yu X, Wen Y, Lin Y, Zhang X, Chen Y, Wang W, Wang G and Zhang L: The value of preoperative glasgow prognostic score and the c-reactive protein to albumin ratio as prognostic factors for long-term survival in pathological $\mathrm{t} 1 \mathrm{n} 0$ esophageal squamous cell carcinoma. J Cancer 9(5): 807, 2018. PMID: 29581759. DOI: $10.7150 /$ jca.22755

9 Han L-H, Jia Y-B, Song Q-X, Wang J-B, Wang N-N and Cheng Y-F: Prognostic significance of preoperative lymphocytemonocyte ratio in patients with resectable esophageal squamous cell carcinoma. Asian Pac J Cancer Prev 16(6): 2245-2250, 2015. PMID: 25824745, DOI: 10.7314/apjcp.2015.16.6.2245

10 Wang L, Wang C, Wang J, Huang X and Cheng Y: A novel systemic immune-inflammation index predicts survival and quality of life of patients after curative resection for esophageal squamous cell carcinoma. J Cancer Res Clin Oncol 143(10): 2077-2086, 2017. PMID: 28601935. DOI: 10.1007/s00432-017-2451-1

11 Ishibashi Y, Tsujimoto H, Hiraki S, Kumano I, Yaguchi Y, Horiguchi $\mathrm{H}$, Nomura $\mathrm{S}$, Ito $\mathrm{N}$, Shinto $\mathrm{E}$ and Aosasa $\mathrm{S}$ : Prognostic value of preoperative systemic immunoinflammatory measures in patients with esophageal cancer. Ann Surg Oncol 25(11): 3288-3299, 2018. PMID: 30019304. DOI: 10.1245/ s10434-018-6651-y
12 Wright JS, Wall HK and Ritchey MD: Million hearts 2022: Small steps are needed for cardiovascular disease prevention. JAMA 320(18): 1857-1858, 2018. PMID: 30193304. DOI: 10.1001/jama.2018.13326

13 Berger JS, Krantz MJ, Kittelson JM and Hiatt WR: Aspirin for the prevention of cardiovascular events in patients with peripheral artery disease: A meta-analysis of randomized trials. JAMA 301(18): 1909-1919, 2009. PMID: 20029786. DOI: 10.1024/1661-8157.98.22.1315

14 Ando N, Kato H, Igaki H, Shinoda M, Ozawa S, Shimizu H, Nakamura T, Yabusaki H, Aoyama N and Kurita A: A randomized trial comparing postoperative adjuvant chemotherapy with cisplatin and 5-fluorouracil versus preoperative chemotherapy for localized advanced squamous cell carcinoma of the thoracic esophagus (jcog9907). Ann Surg Oncol 19(1): 68-74, 2012. PMID: 21879261. DOI: 10.1245/s 10434-011-2049-9

15 Bertero L, Massa F, Metovic J, Zanetti R, Castellano I, Ricardi $\mathrm{U}$, Papotti $\mathrm{M}$ and Cassoni $\mathrm{P}$ : Of the uicc classification of malignant tumours: An overview of the changes in the pathological tnm classification criteria-what has changed and why? Virchows Arch 472(4): 519-531, 2018. PMID: 29209757. DOI: $10.1007 / \mathrm{s} 00428-017-2276-\mathrm{y}$

16 Tsujimoto H, Takahata R, Nomura S, Yaguchi Y, Kumano I, Matsumoto Y, Yoshida K, Horiguchi H, Hiraki S and Ono S: Video-assisted thoracoscopic surgery for esophageal cancer attenuates postoperative systemic responses and pulmonary complications. Surgery 151(5): 667-673, 2012. PMID: 22244180. DOI: $10.1016 / j$.surg.2011.12.006

17 Tsujimoto H, Ono S, Sugasawa H, Ichikura T, Yamamoto J and Hase K: Gastric tube reconstruction by laparoscopy-assisted surgery attenuates postoperative systemic inflammatory response after esophagectomy for esophageal cancer. World J Surg 34(12): 28302836, 2010. PMID: 20703457. DOI: 10.1007/s00268-010-0757-0

18 Ying H-Q, Deng Q-W, He B-S, Pan Y-Q, Wang F, Sun H-L, Chen $\mathrm{J}$, Liu X and Wang S-K: The prognostic value of preoperative nlr, d-nlr, plr and $1 \mathrm{mr}$ for predicting clinical outcome in surgical colorectal cancer patients. Med Oncol 31(12): 305, 2014. PMID: 25355641. DOI: 10.1007/s12032-014-0305-0

19 Feng J-F, Huang Y and Chen Q-X: Preoperative platelet lymphocyte ratio (plr) is superior to neutrophil lymphocyte ratio (nlr) as a predictive factor in patients with esophageal squamous cell carcinoma. World J Surg Oncol 12(1): 58, 2014. PMID: 24641770. DOI: 10.1186/1477-7819-12-58

20 Zhang H, Liu L, Fu S, Liu Y-S, Wang C, Liu T, Liu Z-P, Wang $\mathrm{R}-\mathrm{T}$ and $\mathrm{Yu} \mathrm{K}-\mathrm{J}$ : Higher platelet distribution width predicts poor prognosis in laryngeal cancer. Oncotarget 8(29): 48138, 2017. PMID: 28624815. DOI: 10.18632/oncotarget.18306

$21 \mathrm{Li} \mathrm{S}, \mathrm{Xu} \mathrm{X}$, Liang D, Tian G, Song S and He Y: Prognostic value of blood neutrophil-to-lymphocyte ratio (nlr) and plateletto-lymphocyte ratio (plr) in patients with gastric cancer. Zhonghua Zhong Liu Za Zhi 36(12): 910-915, 2014. PMID: 25623765. DOI: 10.3760/cma.j.issn.0253-3766.2014.12.007

22 Ishibashi Y, Tsujimoto H, Yaguchi Y, Kishi Y and Ueno H: Prognostic significance of systemic inflammatory markers in esophageal cancer: Systematic review and meta-analysis. Annals of Gastroenterological Surgery, 2019. PMID: 32021959. DOI: $10.1002 /$ ags 3.12294 .

23 Garley M, Jabłońska E and Dąbrowska D: Nets in cancer. Tumour Biol 37(11): 14355-14361, 2016. PMID: 27614687. DOI: $10.1007 / \mathrm{s} 13277-016-5328-\mathrm{z}$ 
24 Lapponi MJ, Carestia A, Landoni VI, Rivadeneyra L, Etulain J, Negrotto S, Pozner RG and Schattner M: Regulation of neutrophil extracellular trap formation by anti-inflammatory drugs. J Pharmacol Exp Ther 345(3): 430-437, 2013. PMID: 23536315. DOI: $10.1124 /$ jpet.112.202879

25 Caudrillier A, Kessenbrock K, Gilliss BM, Nguyen JX, Marques MB, Monestier M, Toy P, Werb Z and Looney MR: Platelets induce neutrophil extracellular traps in transfusion-related acute lung injury. J Clin Invest 122(7): 2661-2671, 2012. PMID: 22684106. DOI: $10.1172 /$ JCI61303

26 Bambace $\mathrm{N}$ and Holmes C: The platelet contribution to cancer progression. J Thromb Haemost 9(2): 237-249, 2011. DOI: $10.1111 / \mathrm{j} .15387836 .2010 .04131 . x$

27 Wenzel J, Zeisig R and Fichtner I: Inhibition of metastasis in a murine $4 \mathrm{t} 1$ breast cancer model by liposomes preventing tumor cell-platelet interactions. Clin Exp Metastasis 27(1): 25-34, 2010. PMID: 19916050. DOI: 10.1007/s10585-009-9299-y

28 Rothwell PM, Wilson M, Elwin C-E, Norrving B, Algra A, Warlow CP and Meade TW: Long-term effect of aspirin on colorectal cancer incidence and mortality: 20-year follow-up of five randomised trials. The Lancet 376(9754): 1741-1750, 2010. PMID: 20970847. DOI: 10.1016/S0140-6736(10)61543-7.

29 Tavani A, Gallus S, La Vecchia C, Conti E, Montella M and Franceschi S: Aspirin and ovarian cancer: An italian case-control study. Ann Oncol 11(9): 1171-1173, 2000. PMID: 11061614. DOI: $10.1023 / \mathrm{a}: 1008373616424$

30 Funkhouser EM and Sharp GB: Aspirin and reduced risk of esophageal carcinoma. Cancer 76(7): 1116-1119, 1995. PMID: 8630885. DOI: 10.1002/1097-0142(19951001)76:7<1116::aidcncr2820760703>3.0.co;2-i

31 Kaito K, Otsubo H, Usui N, Yoshida M, Tanno J, Kurihara E, Matsumoto K, Hirata R, Domitsu K and Kobayashi M: Platelet size deviation width, platelet large cell ratio, and mean platelet volume have sufficient sensitivity and specificity in the diagnosis of immune thrombocytopenia. Br J Haematol 128(5): 698-702, 2005. PMID: 15725092. DOI: 10.1111/j.13652141.2004.05357.x
32 Zhang J, Zhang H-Y, Li J, Shao X-Y and Zhang C-X: The elevated nlr, plr and plt may predict the prognosis of patients with colorectal cancer: A systematic review and meta-analysis. Oncotarget 8(40): 68837, 2017. PMID: 28978160. DOI: 10.18632/oncotarget.18575

33 Takeuchi H, Abe M, Takumi Y, Hashimoto T, Kobayashi R, Osoegawa A, Miyawaki M, Okamoto T and Sugio K: The prognostic impact of the platelet distribution width-to-platelet count ratio in patients with breast cancer. PLoS One 12(12): e0189166, 2017. PMID: 29216259. DOI: 10.1371/journal. pone. 0189166

34 Sakin A, Secmeler S, Arici S, Geredeli C, Yasar N, Demir C, Aksaray F and Cihan S: Prognostic significance of mean platelet volume on local advanced non-small cell lung cancer managed with chemoradiotherapy. Sci Rep 9(1): 3959, 2019. PMID: 30850724. DOI: 10.1038/s41598-019-40589-4

35 Gawlita M, Wasilewski J, Osadnik T, Reguła R, Bujak K and Gonera M: Mean platelet volume and platelet-large cell ratio as prognostic factors for coronary artery disease and myocardial infarction. Folia Cardiol 10(6): 418-422, 2015. PMID: 24469872. DOI: $10.5603 / \mathrm{CJ} .2013 .0134$

36 Guo J-C, Lin C-C, Lin C-Y, Hsieh M-S, Kuo H-Y, Lien M-Y, Shao Y-Y, Huang T-C and Hsu C-H: Neutrophil-to-lymphocyte ratio and use of antibiotics associated with prognosis in esophageal squamous cell carcinoma patients receiving immune checkpoint inhibitors. Anticancer Res 39(10): 5675-5682, 2019. PMID: 31570466. DOI: 10.21873/anticanres.13765

Received March 31, 2020

Revised April 8, 2020

Accepted April 10, 2020 